\title{
"Optimum Size" and the Large Science Research Library
}

Techniques for developing optimal size are more meaningful today than they were twenty years ago. Weeding, selective microfilming, and dependence upon neighboring libraries are still useful, but the general framework has radically changed. Exponential curves of growth in research, and in the literature reflecting this research, as well as appearance of entirely new subject areas and proliferation of older disciplines, have produced a new environment. Perhaps the chief emphasis should shift from the old concern about optimal size to exploration of new devices such as establishment of information centers on the Weinberg model and participation by all special libraries in new networks of scientific communication.

W War. large library divisions and departments with special missions, it was probably less meaningful and less critical in the past than it is today, in the face of an ever-mounting flood of scientific and technical publication. National resource libraries, university libraries, and other large research libraries now look ahead ten or twenty years, and predict expenditures of tens of millions and hundreds of millions of dollars for collections, for services, for automation, and for staff. The collection and storage of scientific and technical literature obviously is necessary, but one collection could not provide adequate service, and duplicate collections in every scientific and technical institution obviously are not economically feasible. Since such a procedure is out of the question, each technical library, and all scientific and technical libraries

Dr. Shipman is Director of the Linda Hall library in Kansas City, Missouri. This paper was read at the 1965 annual meeting of the American Society for Engineering Education in Chicago. collectively, face unprecedented problems not only in establishing criteria for optimum size, but also in determining what is of value, and what is economically feasible.

What is the scale of the problem? Contrary to the popular impression that the spectacular burgeoning of scientific research and of publication is a post-war phenomenon, Derek J. de Solla Price points out ${ }^{1}$ that the now-familiar exponential curve of growth had its origins in the seventeenth century, and that, since that time, there has been an annual literature growth of 7 per cent compounded. This works out to growth by a factor of 10 each half-century, and by a factor of one million in the three centuries which separate us this year from the first issue of the Philosophical Transactions of the Royal Society.

Since, quite obviously, scientists produce science and its literature, it is important to consider some of the facts about these producers. Most of the scientists who have ever lived are active

1D. J. de Solla Price, "The Scientific Foundations of Science Policy," Nature, CCVI (April 17, 1965), 233-38. 
and working today, and indeed, perhaps 50 per cent of them have been produced in the past ten years. This is not a new feature in the scientific scene but has been true throughout the previous centuries of modern science. Newton, Faraday, Darwin, Rutherford, and Einstein could say that most of the scientists produced up until their own times were to be numbered among their working colleagues, and that most of them were young. For those of us working with the scientific literature this is significant, because the one distinguishing characteristic of all scientists is that they publish. Publication was and is the lifeblood of science. It has been throughout the past three centuries the prime vehicle of communication, of dissemination, and ultimately, of storage for all scientific knowledge. It was more than that, for as Weinberg has said, "throughout the years the scientific community has developed an empirical method for establishing scientific priorities-deciding what is important in science, and what is not important. This is the scientific literature. ... The process of self-criticism embodied in the literature, though implicit, is nonetheless real and highly significant." 2

Science is a cumulative discipline, and therefore, as Newton observed, in all modesty every creative worker stands on the shoulders of the giants who went before. Today, as Gerald J. Holton of Harvard University said recently, it is more likely that the producing scientist sits in conferences side-by-side with the giants on whose shoulders they stand. Perhaps they are not all giants, but their shoulders still support an immense effort in some of the rapidly growing subject areas. The scientific paper has generally been the accepted vehicle of communication in this process of cumulation, and as Weinberg has suggested, an effective agent in the selection and critical evaluation of the material to be

\footnotetext{
"Alvin M. Weinberg, "Criteria for Scientific Choice," Minerva, I (Winter 1963), 159-71.
}

communicated, disseminated, and stored. Both of these historical functions seem to be in serious jeopardy today.

In the case of communication, how can the million or more articles appearing every year reach more than a tiny fraction of their potential audience? How many people, except for the author, the referees, and the editor, ever read a significant number of these papers? As to dissemination-which can be defined in this context as controlled or directed distribution of the literature to a particular audience, prepared and able to understand it and use it-how can such dissemination possibly be effective in view of the proliferation of the literature, the language barriers, and interdisciplinary complications? While some of the communication and dissemination function has shifted to secondary sources-to the abstracts and the current reviews-these secondary publications have themselves become infected with the virus and in many cases are now so voluminous, so frustrating to use, that they too fail-at least in terms of communication. As a result we now see the phenomenon of the mushrooming published symposia, congresses, and conferences, and colloquia, indicating that scientists may be returning to the old "invisible college" idea, in which personal contact becomes once again the primary device for communication within a fairly close-knit group of specialists. The best of these conference and symposium publications -because they have been presented to a knowledgeable group of peers-have the advantage of built-in critical evaluation. The ideas presented have been criticized and the criticisms embodied in the published summaries or proceedings.

In terms of this selective and critical evaluation of the literature, the proliferation taking place has generally reduced its reliability and effectiveness. For one thing, the wide variety of sponsorship of current publications-journals and serials published by scientific societies, 
or by commercial organizations, or by trade groups, or by government agencies, etc., has resulted in a lack of uniformity or consistency in refereeing, and in critical appraisal. The report literature, now widely dispersed throughout the bibliographic retrieval systems, has sometimes added only bulk-uncritical and nonrefereed papers in great numbers-to still further complicate the picture.

Then, too, there is the Tower of Babel problem. As one nation after another qualifies for membership in the select society of science and technology, new and generally unfamiliar languages (at least in the West), such as Russian, Japanese, and Chinese, appear ever more frequently and, for example in a field such as chemistry, make up more than 50 per cent of the current publications indexed and abstracted in this subject area. In a special abstracting tool, one issue of which I had occasion to consult recently, contained a total of 373 references, 148 of them in Russian, 140 in English and 85 references distributed among eleven other languages.

In spite of all this, I would agree with Ralph Shaw that "our problem does not appear to be one of too much literature. It would be criminally wasteful if the vastly increased research expenditures of recent years did not result in vast (though not proportional) increases in knowledge, and it would be equally wasteful if the new knowledge thus created were not made permanently and generally available." 3 Our research expenditures have doubled on the average every four years since World War II, going from one billion to about eighteen billion dollars in 1965 .

Nor can we challenge the appearance of the new or even the exotic languages in the sciences. As Dr. Price has emphasized, the exponential feature of

"Ralph R. Shaw, "The Function of a Modern Special Library," Research Management, V (November 1962), 485-92. growth in the literature involves differing rates of growth for particular subjects and particular countries at different times. There is some evidence to indicate that, relatively speaking, American, British, and Soviet rates of doubling are slowing down, and that other nations are taking up the slack with an increased acceleration. The results for the early future are then quite obvious in terms of the resulting language distribution in the literature. One English scientist predicted some years ago that by the end of this century more than 50 per cent of the world's scientific literature could be in Chinese.

For the large research library therefore it seems hardly realistic to talk about optimum size techniques without careful consideration of the corrections and adjustments which are called for, and indeed may be already at work within the basic framework of scientific and technical communication.

"Optimum size" has of course always been a relative expression, and the devices used in its pursuit have recognized differences between libraries in size and in function; differences in mission, as well as the increasing interdisciplinary fluidity which has disrupted many a carefully laid scheme for subject coverage and control.

In the past many devices have been used in determination of optimum size. They have included, among others, the following:

1. The establishment of restrictive limits of subject selection.

2. The use of literature citation counts for determining most-used serial titles, as well as for most-used foreign language titles and for the required and desirable time coverage in the acquisition of backfiles.

3. Dependence upon neighboring libraries for particular areas of subject strength, and for breadth of coverage.

4. Extensive use of interlibrary loan to tap more distant library strengths. 
5. Discriminating weeding.

6. Selective microfilming, and the systematic purchase of available microforms.

All of these approaches were and still are practicable and manageable, depending upon the particular library's size, function, objectives, and support. For the special library, the problem apparently is still much the same as it was. To quote Ralph Shaw again, "the need in terms of storage and obtaining materials is simply that of housing those things used frequently enough to justify their space . ... and developing a communication system which would produce the desired material from any source in which it was housed as promptly as it was needed ... the job of the special library is to support the research program for which it is maintained-no more, no less." 4

The catch is in the phrase "as promptly as it was. ..." Here we shift back to the large research library, with all of its unsolved problems and complications regarding "optimum size." Shaw feels that it should not be difficult to "develop a network of intelligence services starting with our great research libraries to provide a reservoir of materials; a series of information centers, with bibliographical and substantive competence to bring together the significant materials, and eliminate redundancy in broad areas of science and technology...." Perhaps it is not so difficult as we think, but at a first look it would seem to require a totally new approach to the literature by the scientist himself, rather than a solution by the traditional custodian of the literature-the librarian and the documentalist. The potential network of great research libraries is available, providing the reservoir of materials and the necessary bibliographical competence. The information centers are already growing in number and in effectiveness and are

+ Ibid., p. 488-89. bringing to bear some of the substantive competence which is the crying need in the current literature situation. It is but a rare beginning, and in spite of the challenges raised by Weinberg, Wigener, Bernal, and many others the working scientist generally has not concerned himself with the primary responsibility which would seem to be his in the total process of evaluation and control of scientific communication.

In looking for the patterns which are necessary for adequate control and management of this communication, our problem is not primarily one of a need for new machines. We have the machine capability, and it will play a vital role, but it seems to me, an ancillary role. Without going into the specific questions of this role, it seems to me that computers will make it possible to do all the jobs we need to do, but they will not themselves do the job.

Weinberg has emphasized the importance of one promising developmentthe emergence of the information center which far transcends our earlier, more limited conceptions of such centers. The new centers will be manned by scientists and by librarians, all dealing with information problems in the broadest sense. Scientists on various levels of the Wigener social hierarchy will try to learn about everything that is published in special fields. They will scrutinize, codify, evaluate, compile, review, and synthesize. Their work will result in published abstracts, bibliographies, compilations of data, compilation of information about instruments, equipment, and techniques. Eventually, on other levels, they will extract, relate and generalize, far more systematically than is done today. The center will handle the difficult questions dealing with its special area of competence-questions which will be referred to it by national, regional, state, and local referral centers-probably located in the libraries representing these

(Continued on page 392 ) 
Stockpiling of extra copies of noncopyrighted journal articles which have been photocopied once, or more likely more than once, might be studied. This examination should be from the viewpoint of considering storage costs for items which may never be asked for again, as well as production costs, and relating them to the present practice of photocopying only on demand, albeit if sometimes repeatedly.

\section{OPTIMUM SIZE . . .}

(Continued from page 357 )

areas. These libraries will depend upon the centers for their published output as an important device for aiding in the evaluation, digestion, and manageable assimilation of the literature for which they are responsible.

In such a development, all libraries could approach the problems of optimum size and of division of subject responsibility confidently and rationally.

There is considerable evidence that the great research libraries-government, university, and private-are already making tentative shifts to prepare themselves for their proper roles in the network of collections and services which must eventually evolve if we are to solve our problems. The national libraries of medicine, of agriculture, and other remarkable concentrations of subject strengths in various government departmental libraries are becoming accepted as true national resource centers, as indeed they have long tacitly been. There is much talk about the establishment of regional branches throughout the country. The Department of Agriculture has had socalled branches for many years, but not on the scale suggested here. The Library of Congress, which established a science and technology division only after World War II, and of course has tremendous resources and capabilities, is a central point in this shift and will spearhead many of the costly experiments and programs necessary to achieve it.

University libraries, for the first time, are separating their research functions in separate buildings, foreshadowing coming changes in function. At least one of them, Yale University, is separating its science research materials and will concentrate them in a new building.

The former Midwest Inter-Library Center has changed its name, and, from all indications, its future role in the research library picture in the nation. John Crerar and the Linda Hall libraries are becoming increasingly national resources, rather than limited local or regional library features. In Great Britain, the national lending library of science is a well established, working entity, and plans for a national science reference library are well along.

In conclusion, it might be said that "optimum size" techniques may need to be related to a situation in the scientific literature and in scientific libraries, which show every indication of radical and extensive changes ahead. These changes will come very quickly, for the pace of achievements in new knowledge and in new literature, which demands these changes, give us very little time. 